\title{
The way of College English teachers' innovation and development under the network environment
}

\author{
Maohua SUN \\ Foreign Language Department, Dalian Jiao Tong University, Liaoning Province, China \\ summer_817@163.com
}

Keywords: College English teachers; teachers' quality; innovation and development .

\begin{abstract}
Internet + era, information technology to the educational reform has brought new vitality and vigorous development of the fertile soil, has brought revolutionary changes to the English teaching and learning in the new situation, College English teachers should optimize the knowledge structure, improve the quality and enhance the information literacy of teachers, the formation of multiple learning community, establish lifelong consciousness of development, to meet the needs of the international background of high-level talents training needs of the community. The learning community promotes the development of teachers' subjectivity. It promotes teachers' knowledge sharing, promotes teachers' effectiveness and creates a dynamic environment for teachers' learning by enhancing teachers' practical wisdom. The establishment of a self-organized teacher education organization and a compound teacher learning model have pointed out the direction for building a learning community.
\end{abstract}

\section{网络环境下大学英语教师创新发展途径 \\ 孙茂华 \\ 大连交通大学, 大连, 辽宁省, 中国 summer_817@163.com}

关键词：大学英语教师; 教师素质; 创新发展

中文摘要. “互联网+” 时代来临, 信息技术给教育教学改革带来了崭新的生机和蓬勃发展 的沃土, 给英语教学和学习带来了革命性的改变, 在这些新形势下, 大学英语教师应优化知 识结构、提高双师素质、提升信息素养、形成多元学习共同体、树立终身发展意识, 以满足 培养社会需求的具有国际化背景的高层次应用型人才的需要。学习共同体促进教师的主体性 发展为导向, 通过提升教师实践性智慧为途径, 促进教师知识共享、提升教师效能、创建教 师学习的动态环境。建立自组织结构的教师教育组织和复合的教师学习模式为构建学习共同 体指明了方向。

\section{1. 网络环境下大学英语教师创新发展的必要性}

首先祝贺您的论文被本次大会录用。为了顺利、高质量地做好本次会议论文集的出版工 作, 本文给出了论文最终版本的格式要求, 请各位作者务必按照本文给出的论文格式要求编 辑、排版您的论文, 以使得您的论文能顺利入选会议论文集。在此大会组委会非常感谢您的 配合和支持。 


\section{1 培养国际化人才的需要}

在经济全球化和我国社会主义现代化建设步入新的关键历史时期, 随着 “中国制造2025” “一带一路” 等重大战略的提出, 新一轮科技革命和产业变革蓄势待发, 为更好地践行高等 教育的历史使命, 为经济社会发展提供高素质的人才保障和智力支持, 特别需要加快培育具 有国际视野的高层次应用型人才。《国家中长期教育改革和发展规划纲要》（2010-2020）（以 下简称《规划纲要》) 明确指出: “要适应国家经济对外开放的要求, 培养大批具有国际视 野和通晓国际规则, 能够参与国际事务和国际竞争的国际化人才。” 但是, 目前的大学英语 教育离培养具有国际视野、通晓国际规则的高水平外语人才的目标还有很大一段距离 [1]。

\section{2 高校转型发展的需要}

很多高校还处在转型阶段, 应用型本科院校教师要有与专业相结合的实践经验和技术应 用能力, 大学英语课虽为公共课, 但是在培育具有国际视野的高层次应用型人才中起着举足 轻重的作用。新时代对大学英语教师的知识结构和能力结构要求越来越高, 但是很多大学英 语教师没有跨学科专业知识, 没有相关行业工作经验, 制约着应用型人才培养质量, 影响学 校转型步伐。

\section{3 服务地方区域经济发展的需要}

应用型本科院校的产生和发展与地方经济、行业、企业有着天然的联系, 它必须根植地 方, 面向企业发展需求培养人才。产业的不断升级和换代除了对人才的需求有了更高的要求, 同样, 对从业人员的英语水平和英语知识提出了不同的要求。《意见》提出高校转型要坚持 需求导向、服务地方。应用型本科要加快融入区域经济社会发展, 更好地与当地创新要素资 源对接, 与经济开发区、产业聚集区创新发展对接, 与行业企业人才培养和技术创新需求对 接。

在经济飞速发展的现代社会, 随着产业的升级与不断换代, 各行业对应用型人才的需求 发生极大的变化, 这对大学英语教学提出了不同的要求, 大学英语课程要培养学生用英语作 为工具从事与本学科专业相关工作的能力, 故很多大学纷纷进行英语教学目标、教学内容的 调整, 以满足区域经济发展、服务应用型人才培养需要。但是长期以来, 大学英语教师习惯 于进行基础英语教学, 讲授语言知识和进行语言技能训练, 知识结构单一, 缺乏广度和深度, 无法培养满足地方经济发展需要的人才。

\section{4 教育信息化发展的需要}

随着科学技术的发展, “互联网十”时代来临, 信息技术融入到了社会的各个领域。信 息技术给教育教学改革带来了崭新的生机和蓬勃发展的沃土, 给英语教学和学习带来了革命 性的改变, 慕课、微课、翻转课堂纷纷来袭。《规划纲要》指出 “强化信息技术应用, 提高 教师应用信息技术水平, 更新教学观念, 改进教学方法, 提高教学效果”。信息技术的高速 发展对传统英语教学带来巨大冲击, 很多大学英语教师无所适从, 信息技术和英语课堂整合 能力不强, 从而制约了英语教育教学改革的步伐, 束缚了教育信息化教学手段的运用, 教学 效率低, 教学效果不理想, 无法满足学生的多元需求。

\section{5 大学英语课程改革和发展的需要}

随着我国改革开放的不断深化, 国家和社会对具有较高外语水平和国际交往能力的复合 型人才的需求大量增加, 大学生的外语语言能力已成为衡量高等学校教学质量的重要标志之 一。教育部《大学英语课程教学要求》提出 “教师素质是提高教学质量的关键, 也是大学英 语课程建设与发展的关键” 。随着我国经济与社会的高速发展, 我国加大了对英语人才的需 求, 高校也积极响应国家的需求, 对大学英语教学进行了改革, 以求培养出更多优秀的英语 人才 $[2]$ 。很多高校在逐步转型, 大学英语课程也经历着变革, 在课程开设、教学内容、教学 
目标等方面都进行了调整, 这无疑对教师的素质、能力的提升及知识结构的优化提出了更多 更高的要求。大学英语教师的创新发展是形势的需要, 是对应用型人才培养的必要回应, 是 区域经济发展的有力保障。

\section{2. 学习共同体是教师专业成长的有效组织}

与传统的学校教研组相比, 教师学习共同体的组织结构松散而开放, 活动内容综合且多 元, 活动方式更具互动性, 活动主体更具自主性和平等性, 因而在教师的专业成长中发挥着 重要作用。

\section{1 提升教师的实践性智慧}

教师实践性智慧是教师专业发展的核心，关注实践性智慧的发展是现代教师教育的重要 内容, 教师实践性智慧的获得不能靠 “授课” 式的教师培训模式, 有效的策略和方法是使教 师以课堂教学中实际的问题解决为途径, 以学科教研活动为平台, 开展主题式教研活动, 实 现教师自主的实践反思与专家和同辈的交互作用。传统的教师知识观排斥了教师在形成知识 过程中的实践性，而新的知识观则指出实践在教师知识形成中的重要意义。教师的两种知识, 一是公共知识, 二是实践知识。前者是不具有信念、判断等价值成分的知识, 而后者则包含 了各种价值判断。教师的知识更多地不是来自于公共领域的, 而是来源于教师在教育现场中通 过种种实践与体验而形成的经验总结。教师专业知识与能力结构体系的不断充实和进一步完 善是在教学实践中逐步实现的。教师在实践中对教育意义的主动探求, 将提升教师的教育责 任感和理论思维能力，使教师对教育、学校乃至自身的存在与发展有更深入的理解。

\section{2 促进教师知识共享}

在教师学习共同体中，知识的创造产生在教师相互交流沟通、分享过程中。教师的知识 包括显性知识 (Codlif ied 或Explicit) 如学科知识与隐性知识 (tacit 或hidden) 如教师个 体实践知识, 而教师学习共同体就是不断转化这两种知识类型的媒介, 教师通过组织内的互 动学习, 使显性知识与隐性知识相互转化, 不同教师个体利用和传递不同的知识经验, 在相 互交流中生成新的知识, 实现知识的创新, 促进教师知识的有效增值。教师知识共享的重要 任务是促进教师成员的知识创新, 通过知识创新扩充组织的知识积累, 促进教师的专业发展 和学校的发展。而学校知识创新的实质就是显性知识和隐性知识之间相互作用而形成的知识 的转化而后增值的过程。因此在学习共同体中，教师的知识共享是呈隐性一一一显性 隐性螺旋式转化过程, 教师不断获得知识的质与知识的量方面提高, 促进专业化成长。 运用学习共同体形式进行知识共享可以帮助教师分享其他教师工作的经验与教训, 从而有效 地建构与管理自己的专业知识。在学习共同体中, 教师通过分享会生成出许多观点、想法与 理解，逐渐形成共同体的知识，从而有效激发教师团队的专业成长。

\section{3 提升教师效能}

教师的自我效能感 (sense of self -ef ficacy) 指 “他们对自己是否有能力对学生学习 产生积极影响的信念”，一般包括教师的个人教学效能感和一般教育效能感两个方面 [ 4]。 自我效能的形成过程实质上就是个人整合自我效能信息并形成效能的自我信念, 从而达成组 目标 [5]。教师正是通过选择、比较和整合各种成功与失败的信息, 形成了教师的自我效能 在教师学习共同体中, 教师通过教学实践问题的沟通和学习, 影响其教学观念、教学目标、 教学方式及教学评价等理念而后进行实践操作进而反思, 在不断的实践一一一反思———实 践的循环过程中, 促进了教师的教学改进, 增强了教师的专业能力。在这个过程中, 教师个体 效能感增强, 在教学实践中教师表现出积极的教学革新、良好的协作性与职业认同感, 教师 集体效能感也增强, 发展了教师集体的一种知觉, 更进一步反作用于教师学习共同体, 促进 二者相互发展。教师的自我效能感来自于工作实践, 并且对学生产生积极影响, 自我效能感 
较强的教师对教育工作通常抱有积极的看法, 同时也认为自己具有较强的教育能力和教育影 响力 [6]。教师的教育能力在教育工作中可以得到不断的发展, 并且产生促进性的、适应性 的工作动机, 教师为自己设定和选择富有挑战性的任务与目标, 并积极努力地使自己的行为 和活动朝向这些目标，在面对困难时也往往更能主动积极地想办法克服并更加努力地坚持下 去。这种良好的、适当的动机最终也将促进教师教育行为的改善, 并不断促进其教育能力与 教育有效性的提高。

\section{4 生成教师学习的动态环境}

教师学习的环境不断变化才能刺激教师的学习渴望, 而教师工作的物质环境相对稳定, 因而只有通过改变教师对学习环境的态度与思维方式, 才能使精神环境改变。在学校建立学 习的动态环境可以使教师在学习过程中统一学校的办学理念和校园文化, 教师通过终身性的 学习提高教学的质量 [7]。在环境改变过程中教师的自我反思因素非常重要, 而在教师学习 共同体中, 教师群体的相互协作、相互交流与沟通对改变教师的思想行为、培养教师的自我 反思意识是很重要的途径。教师个体在学习共同体其他成员的帮助与支持下，更容易从不同 角度发现自己的问题与不足, 寻找到解决对策, 在不同的交流意见与方案中, 使教师处于学 习的扶持环境中, 在这里他们能达到自己的目标和寻找新的起点。在这一过程中, 针对不同 的境况提出不同的学习策略, 教师之间能形成相互协作、相互学习的不断变化的环境, 促进教 师找寻到不同专业发展的起点, 在动态的环境中不断调整自己而不断发展。在动态的学习环 境中, 教师通过学习来不断改善自己的教育教学行为, 不断挖掘自己的教育教学能力, 这样 可以使学习与实践形成良性互动, 使教师看到自己的学习效果, 进而增强学习的动力和持久 力。

\section{3. 总结}

形势在不断变化，作为大学英语教师，一定要顺应时代的变化和经济的发展。教师的知 识储备及教学技能不是一劳永逸的, 教学内容、教学方法和手段等都要与时俱进, 故教师要 树立终身发展意识: 进行长期学习, 不断学习新理论、新知识, 实现自身理论水平的提高; 进行反思性教学, 有问题意识, 将教学中发现的问题作为教研教改的突破口; 进行观摩学习、 协作探讨, 参加专题研讨; 经常参加学术会议, 进行学术交流, 了解本领域学术研究动态, 拓宽理论视野, 明晰研究方向。《规划纲要》指出 “教育大计, 教师为本。有好的教师, 才 有好的教育。” 转型背景下, 大学英语教师的创新发展刻不容缓, 是社会经济发展的要求, 也是大学英语教学改革与发展的需要。大学英语教师要响应时代的号召, 积极进取, 不断探 索，为我国培养具有国际视野的应用技术人才做出应有的贡献。

\section{References}

[1] Zhu Xueyuan. The predicament and the way of reform and development of College English education in China under the new situation [J]. Jiangsu high education, 2017 (1): 43-45

[2] Guo Ning. The role of teachers in the period of College English Teaching Reform -- Comment on $[\mathrm{J}]$. educational theory and practice of English teaching reform and teacher development research, 2017 (5): 2

[3] Liu Huppert. College English teachers interdisciplinary academic research [J]. the transformation and development of the theory and practice of education, 2014 (21): 39-40

[4] Zhang Jingyao. Professional development of College English teachers' new ideas -- Comment on "network environment [J]. research" professional development of College English teachers Chinese Education Journal, 2016 (1): 134 
[5] Guo Yan, Xu Jinfen. Research on the construction of College English teacher professional development community in China [J]. foreign language circle, 2015 (5): 79-87 